\title{
EDITORIAL
}

\section{New Directions in a Warming World}

\author{
William Timothy Treal Taylor ${ }^{1}$, E. James Dixon, ${ }^{2}$ \\ Albert Hafner, ${ }^{3}$ Martin Hinz ${ }^{3}$
}

1. University of Colorado, Boulder

2. University of New Mexico

3. University of Bern

As the Journal of Glacial Archaeology publishes its fifth volume, we also find ourselves observing the thirty-year anniversary of the discovery of the iceman Ötzi (the Tisenjoch iceman). Although artifacts were reported melting from ancient ice for many decades prior to the iceman's emergence from a glacier in the Tyrolean Alps, his discovery captured the imagination of the press, the public, and researchers around the world. Found protruding from the ice on the alpine border of Italy and Austria in fall of 1991, his discovery was a watershed moment in the archaeological research of glaciers and ice patches. Analysis of his remains, clothing, and tools underscored the international and interdisciplinary importance of glacial archaeology. This landmark discovery continues to reveal the detailed and personal aspects of his life and death and illustrates to people around the globe that climate change is real. In the years since, glacial archaeology has crystalized into a scientific subdiscipline with important implications for the modern world.

The accelerating impacts of global warming continue to exhume fragile, important frozen materials from the world's high altitude and high latitude environments. As a consequence, melting ice and the traces of the ancient world continue to emerge, and glacial archaeologists have applied increasingly sophisticated scientific methods to locate, analyze, and interpret these unique sites. The discipline has grown from responding to finds as one-of-a-kind, happenstance discoveries to a more holistic international approach rooted in interdisciplinary science. The papers in this volume showcase the growing recognition of glaciers and ice patches as important archives of cultural and biological knowledge that provide new and significant insights into the deep past. 
In the spirit of the international awakening following the Tisenjoch iceman's discovery, a contribution by Junkmanns and colleagues in this issue of JGA reveals new and detailed aspects of previously unknown organic material culture. This meticulous analysis of a composite bow case made of birch bark, rawhide, and other perishable materials provides the first tangible example of this type of technology in a Neolithic archaeological context. The object's stunning preservation enables the authors to reconstruct the technology and techniques used in its manufacture. This discovery, and many others from ice patches over the past decades, fill crucial gaps in our understanding of perishable material culture. In contrast, the manuscript by Labelle et al. (this volume) highlights the equally significant role of mountain ice as repositories of ancient biological information in Colorado's Rocky Mountains. Their analysis of these sites reveals use of high-altitude zones containing perennial ice by animals known to be human prey including bighorn sheep, elk, deer, and bison. Macrofossils such as frozen trees document ecological changes in timberline elevation in response to past climate changes. The dual role of ice patches as repositories for artifacts and paleoecological records demonstrate that ice patch research occupies a central role for understanding past human-environmental interactions.

Glacial archaeology has increased in geographic scope and employed new research methods and emerging technologies, as showcased by the contributions in this volume. Ackermann and colleagues add to a growing analytical toolkit for glacial archaeology, experimenting with the use of geophysics and ground penetrating radar to better understand the landscape and stratigraphy of significant ice patches in the region of North America's Yellowstone National Park. Meanwhile, Caspari (this volume) draws attention the growing importance of remote sensing in glacial and ice patch archaeology research designs, as satellite imagery improves in both resolution and coverage across remote environments.

Following the international publicity surrounding the iceman's discovery, glacial archaeology research has increased in alpine Europe and high-latitude or high-altitude zones on nearly every continent. Important organic artifact discoveries and archaeological and environmental research projects are now ongoing in Scandinavia, the Siberian Arctic, Alaska, the Canadian Arctic and Subarctic, Greenland, North America's Rocky Mountains, and the South American Andes. Clark et al. (this volume) articulate the significance of glacial archaeology and other frozen heritage in the mountains and steppes of Mongolia, where organic materials from the ice fill important gaps in the archaeological record.

Continued climate warming requires researchers, indigenous people, resource managers, and heritage specialists to recognize the urgent need for action and sustained archaeological and preservation efforts. LaBelle and colleagues (this volume) found that in the space of a decade, many promising ice patches previously identified as research targets had melted completely before they could be surveyed. Similar observations have confirmed the disappearance of these important sites in many other areas throughout the world. In some regions, mountain ice may hold the only hope to understand ancient social and environmental changes that shaped our past and our present. Without fieldwork, the surviving scientific datasets may be forever 
lost. In coming years JGA will face the challenge in the effort to preserve these unique records by providing a venue for reporting these discoveries and sharing new concepts to encourage high-caliber scientific research and important heritage values that increase understanding of the past and our future in a melting world.

\section{About the authors}

E. James Dixon is Professor Emeritus of Anthropology and the former Director Maxwell Museum of Anthropology at the University of New Mexico (2007-2016). His areas of research include Arctic archeology, Paleoindian archeology, high altitude and high latitude adaptations, and museum science. He has published three books and more than seventy journal articles and book chapters. He served as a member of the National Science Foundation's Advisory Committee for the Geosciences (2014-2017), and the Advisory Committee for the Office of Polar Programs (2017-2018).

Albert Hafner is Professor and Head of the Department of Prehistory and Co-director of the Institute for Archaeological Sciences at the University of Bern/Switzerland. He studied Prehistory, Anthropology and Geobotanics in Germany at the Universities of Tübingen and Freiburg im Breisgau. His professional career began with excavations in Neolithic and Bronze Age wetland sites in Southern Germany and has conducted large scale rescue excavations in Swiss lake dwellings. He was in the core group of the UNESCO world heritage project "Prehistoric pile-dwellings around the Alps." He was responsible for the Schnidejoch expedition team and edited the publication of this high-alpine ice patch site from the Bernese Alps with finds from the Early Neolithic to the Middle Ages. In 2012 he was elected a member of ICOMOS ICUCH (Int. Council of Monuments and Sites, Int. Comm. of Underwater Cultural Heritage) and SPARC (Snow Patch Archaeology Research Cooperation).

William Taylor is Asistant Professor and Curator of Archaeology at University of Colorado Boulder, USA. His research focuses on the relationship between humans and animals, with a topical focus on horses and animal domestication, and a technical emphasis on archaeozoology, archaeological science, and emerging technologies. He has ongoing field projects in the Great Plains and the American Southwest as well as Mongolia and the Steppes of Central Asia. He also conducts museum collections research in China, Australia, and South America.

Martin Hinz, University of Bern, Switzerland is Managing Editor of the Journal of Glacial Archaeology. He studied Archaeology, European Ethnology and Computer Science in Germany at the Universities of Berlin and Kiel. After his PhD he worked in Kiel for several years as Assistant Coordinator for the DFG Priority Programme SPP 1400 "Early Monumentality and Social Differentiation." His current focus is the combination of scientific data, quantitative methods and archaeological knowledge. In terms of research topics he is particularly interested in the Neolithic and Bronze Age in Switzerland and the influence and question of the determinism of environmental influences on settlement behaviour and prosperity of past societies also in marginal areas. Since 2018 he holds a position as senior researcher at the Institute for Archaeological Sciences at the University of Bern/Switzerland. 